\title{
em um mundo para gente grande, o que podem os corpos pequenos?
}

\author{
laíra assunção braga1 \\ universidade federal do espírito santo \\ orcid id: https:/ / orcid.org/0000-0001-5704-1899 \\ jésio zamboni2 \\ universidade federal do espírito santo \\ orcid id: https:/ / orcid.org/0000-0002-0360-7284 \\ alexsandro rodrigues 3 \\ universidade federal do espírito santo \\ orcid id: https:/ / orcid.org/0000-0002-5998-4978
}

resumo

O texto parte de uma pesquisa de mestrado apresentada ao Programa de Pós Graduação em Psicologia Institucional, da Universidade Federal do Espírito Santo, apresentada no ano de 2019 e que se propôs a trabalhar, junto às crianças, as relações e negociações feitas com as normas de gênero e sexualidade. As crianças apareceram em situações e lugares diversos, com destaque para duas pracinhas de bairro, onde se deu a maior parte da pesquisa. A dissertação não tinha como objetivo fazer uso de teorias desenvolvimentistas, descrever e enquadrar as crianças em categorias, pois entendeu-se que isso também seria a reprodução das lógicas adultocêntricas. Movimentos crianceiros foram considerados em sua potência de existir por si e, por essa autonomia, foi possível visualizar como eles conseguem fazer questão sobre os lugares e identidades que os adultos insistem em reafirmar sobre os corpos através da diferença sexual. Os resultados da pesquisa apontaram que as crianças conseguem agir taticamente dentro das questões de gênero, subvertendo a lógica das estratégias que incidem sobre seus corpos e os colocam constantemente na posição de projetos de adultos. A partir da pesquisa, pensamos como as crianças podem indicar, nos diversos campos de experiência humana, outros modos de se relacionar e estar no mundo.

palavras-chave: crianças; adultocentrismo; táticas; gênero.

\section{en un mundo para gente grande, ¿qué pueden hacer los cuerpos pequeños?}

resumen

El texto es parte de una investigación de maestría en el Programa de Posgrado en Psicología Institucional de la Universidad Federal de Espírito Santo, presentado en 2019, que tenía como propósito trabajar con niños y niñas las relaciones y negociaciones realizadas con las normas de género y sexualidad. Niños y niñas aparecen en diferentes situaciones y lugares mayormente en dos plazas de barrio donde sucedió la mayor parte de la investigación. La tesis no pretendía hacer uso de teorías del desarrollo, describir y clasificar a niños y niñas en categorías, ya que se entendía que esto también sería la reproducción del adultocentrismo. Los movimientos de niños y niñas fueron considerados en su poder para existir para sí mismos y a través de esta autonomía fue posible visualizar cómo logran cuestionar los lugares e identidades que los adultos insisten en re-afirmar sobre sus cuerpos a través de la diferencia sexual. Los resultados de la investigación indicaron que niños y niñas pueden

\footnotetext{
1 E-mail: lairassuncao@gmail.com

2 E-mail: jesiozamboni@gmail.com

3 E-mail: xela_alex@bol.com.br
} 
actuar tácticamente dentro de los problemas de género subvirtiendo la lógica de las estrategias que se centran en sus cuerpos y los colocan constantemente en la posición de proyectos de adultos. A partir de la investigación pensamos en cómo niños y niñas pueden indicar en los diversos campos de la experiencia humana otras formas de relacionarse y estar en el mundo.

palabras clave: niños- niñas; adultocentrismo; tácticas; género.

\section{in a world for big people, what can small bodies do?}

\section{abstract}

The text is part of a masters research presented to the Postgraduate Program in Institutional Psychology of the Federal University of Espírito Santo, presented in 2019 and that proposed to work with the children, the relations and negotiations made with the norms of gender and sexuality. The children approach was in different situations and places but often on two neighborhood squares, where most of the research took place. The dissertation was not intended to use developmentalist theories, describe and classify children into categories, because it was understood that these would also be the replication of adultcentered logic. Childhood movements and cleverness were considered in their power to exist by themselves and through this autonomy it was possible to visualize how they can make a point about the places and identities that adults insist on reaffirming about their bodies through sexual difference. The research results indicated the children can act tactically within gender issues, subverting the logic of strategies that focus on their bodies and constantly place them in the position of an adult in the making. From research, we think about how children can indicate, in various fields of human experience, other ways to relate and be in the world.

key words: children; adultcentrism; tactics; gender. 
em um mundo para gente grande, o que podem os corpos pequenos?

\section{construindo caminhos com as crianças}

Este texto parte de uma pesquisa de mestrado, apresentada ao Programa de Pós Graduação em Psicologia Institucional, da Universidade Federal do Espírito Santo, desenvolvida entre os anos de 2017 a 2019. A dissertação foi intitulada como "O que podem as crianças quando a maquinaria corpo-gênero-sexualidade falha?". Trata-se de um trabalho sobre como as crianças estabelecem relação com as normas de gênero e sexualidade, utilizando-se como aposta metodológica as pesquisas com cotidianos. Como campo, foram pensadas inicialmente as praças públicas no município de Vitória, no Espírito Santo, e outros espaços de convivência que se tornaram possíveis no desenvolvimento da pesquisa. Nestas primeiras linhas, oferecemos aos leitores o que pensamos e com quem dialogamos em nossas compreensões sobre sexualidade e que nos permite ampliarmos com esta categoria de análise a ideia de criança como novidade e força criadora que a perseguimos. Com as palavras de Michel Foucault (2014), gostamos de afirmar com o mesmo que:

A sexualidade faz parte de nossas condutas. Ela faz parte da liberdade de que gozamos neste mundo. A sexualidade é algo que nós criamos nós mesmos - ela e nossa própria criação, muito mais do que a descoberta de um aspecto secreto de nosso desejo. Devemos compreender que, com nossos desejos, através deles, se instauram novas formas de relações, novas formas de amor e novas formas de criação. O sexo não é uma fatalidade: ele é uma possibilidade de chegar a uma vida criadora. (FOUCAULT, 2014, p.251)

Nesta perspectiva de tomar a sexualidade como força criadora e efeitos de liberdade, encontramos com as crianças ariscas que nos habitam como novidade, força criadora, que circulam entre nós em exercícios de poder e nos permitem, na mais íntima relação com uma certa experiência que não se capitaliza com o corpo, gênero e sexualidade, desejar, entre existências fugazes a sustentação de uma vida crianceira que pede passagem em atos criativos e subversivos. Logo, a criança como novidade, condição da vida e de uma vida, presença em todos nós, é fonte criadora e possibilidade que se abre para outros modos de vida, afetos e forças. 
Pensar a criança como força criadora é também pensar na fragilidade das engrenagens normalizadoras dos dispositivos da sexualidade e da infância. Nossa criança possui um corpo, não é somente da ordem de pensamento e ficção. Logo, o corpo crianceiro, novidade em si, marcado pelas políticas de gênero e sexualidades, reivindica presença e sustentação. Segundo Judith Butler,

[...] a corporificação implicada pelo gênero e pela performance é dependente das estruturas institucionais e dos modos sociais mais amplos. Não podemos falar sobre um corpo sem saber o que sustenta esse corpo, e qual pode ser a sua relação com esse apoio ou falta de apoio. Desse modo, o corpo é menos uma entidade do que um conjunto vivo de relações; o corpo não pode ser dissociado das condições ambientais de infraestrutura da sua vida e da sua ação. Sua ação é sempre uma ação condicionada, que é sentido do caráter histórico do corpo, além disso, humanos e outras criaturas dependem do apoio da infraestrutura, de maneira que isso expõe uma vulnerabilidade específica que temos quando ficamos sem apoio, quando as condições de infraestrutura começam a se decompor, ou quando nos encontramos radicalmente sem apoio em condições de precariedade (BUTLER, 2018, p.72).

Nesse encaminhamento, realçamos com Foucault (2014) e com Butler (2018) possibilidades de pensarmos sexualidade, infância e o corpo que importa, como formação histórica que comportam limites de saber e poder. Sexualidade, infância e uma forma, um corpo com estatuto de humano, estratégias dominantes da disciplina e controle da população estão a serviço da norma e de um projeto de identidade (hetero) normalizadora. A criança, novidade no mundo, acontecências que se valem de instantes e de uma vida toda, não se presta a este objetivo e não se coloca a serviço desse projeto. A criança como novidade é força que não se capitaliza entre regulações e regulamentações. A criança como acontecimento, em seu direito de aparecer, porque corporificada quando encontra as condições que sustentam uma vida, assombra nossos saberes sobre o dispositivo da infância e da sexualidade. Ela, a criança como novidade, aparece na justa medida do presente vivido. Em atos, acontecimentos e efeitos no seu corpo, corpo este que se recusa a assumir projetos identitários acoplados aos privilégios do sistema sexo-gênero, desse modo, um corpo capaz de fazer o dispositivo da sexualidade e da infância entrar em curto-circuito. Sobre o dispositivo, Michel Foucault (2014), enuncia que: 
O que eu tento descobrir sob esse nome é, primeiramente, um conjunto decididamente heterogêneo, que comporta discursos, instituições arranjos arquitetônicos, decisões regulamentares, leis, medidas administrativas, enunciados científicos, proposições filosóficas, morais, filantrópicas, em resumo: do dito, tanto do não dito, eis os elementos do dispositivo. O dispositivo propriamente é a rede que se pode estabelecer entre esses elementos. [...] o dispositivo é exatamente a natureza do laço que se pode existir entre estes elementos heterogêneos. [...] por dispositivo entendo uma espécie - digamos - de formação, que, em um determinado momento histórico, teve por função maior responder a uma urgência. $O$ dispositivo tem, pois, uma função estratégica dominante. [...] Eu disse que o dispositivo era de natureza estratégica, o que supõe que se trata aí de uma manipulação de relações de força, seja para desenvolvê-las em uma direção, seja para bloqueá-las, ou para estabilizá-las. Utilizá-las. O dispositivo está, então, sempre inscrito em um jogo de poder, mas sempre ligado também, a um ou alguns limites de saber, que nascem dele, mas também o condicionam. É isto o dispositivo: estratégias de relações de forças suportando tipos de saber e suportadas por eles. FOUCAULT, 2014, p.45)

Apontando nossas incursões, entre o dispositivo e a sexualidade e compreendendo que este é uma das peças das engrenagens de jogos de poder e saber, tomamos as crianças em novidade como força capaz de contradispositivar as estratégias de poder da norma do adulto e da polícia de plantão do sistema sexo-gênero. Com esta pequena incursão, retomamos o que sustenta este texto, ou seja, uma dissertação. A dissertação construída com as crianças se debruçou sobre o modo como os gêneros são praticados e reconhecidos, expondo seu caráter performático em contraponto às noções que buscam essência ou naturalidade nas expressões de gênero. Por performance aqui, entendemos com Butler (2003), um conjunto de gestualidades, artefatos, códigos e linguagens que vão se produzindo em um corpo e o inserem no sistema de significação da diferença sexual. Entendemos que as crianças que compuseram a pesquisa conseguiram expor o caráter produtivo e não essencial dos gêneros. Provocando a polícia de plantão das normas de gênero e sexualidade, sobre atos performativos, Judith Bulter (2003), contribui conosco ao compreender que:

[...] o gênero é uma identidade tenuemente construída no tempo, instituído num espaço externo por meio de repetição estilizada de atos. O efeito do gênero se produz pela estilização do corpo e deve ser entendido, consequentemente como, como forma corriqueira 
pela qual os gestos, movimentos e estilos corporais de vários tipos constituem a ilusão de um eu permanente marcado pelo gênero. Essa formulação tira a concepção do gênero do solo de um modelo substancial da identidade, deslocando-a para um outro que requer concebê-lo como uma temporalidade social constituída. Significativamente, se o gênero é instituído mediante atos internamente descontínuos, então a aparência de substância é precisamente isso, uma identidade construída, uma realização performativa em que a plateia social mundana, incluindo os próprios atores, passa a acreditar, exercendo-a sob a forma de uma crença. $\mathrm{O}$ gênero também é uma norma que nunca pode ser completamente internalizada: o interno é uma significação de superfície. E as normas do gênero são afinal fantasísticas, impossíveis de incorporar. Se a base da identidade de gênero é a repetição estilizada de atos ao longo do tempo, e não uma identidade aparentemente sem suturas, então a metáfora espacial de uma base é deslocada e se revela como configuração estilizada, a rigor, uma corporificação do tempo com marca de gênero. Mostrar-se-á então que o eu de gênero permanente é estruturado por atos repetidos que buscam aproximar o ideal de uma base substancial de identidade, mas revelador, em sua descontinuidade ocasional, de falta de fundamento temporal e contingente dessa base. É precisamente nas relações arbitrárias entre atos que se encontram possibilidades de transformação do gênero, na possibilidade da incapacidade de repetir, uma deformidade, ou uma repetição parodística que denuncie o efeito fantasístico da identidade permanente como uma construção politicamente tênue.(...) $\mathrm{O}$ fato de a realidade do gênero ser criada mediante performances sociais continuas significa que as próprias noções de sexo essencial e de masculinidade e feminilidade verdadeiras ou permanentes também são constituídas, como parte da estratégia que oculta o caráter performativo do gênero e as possibilidades performativas de proliferação das configurações de gênero fora das estruturas restritivas da dominação masculinista e da heterossexualidade compulsória. (BUTLER, 2003, p. 200/201)

Seguindo, a partir das contribuições de Butler (2003), esta dissertação além de se ocupar dos anúncios que as crianças fizeram sobre como vivem corpo, gênero e sexualidades, a pesquisa também considerou o modo como elas os fizeram. As crianças da pesquisa desfizeram os argumentos essencialistas das normas de gênero a partir da diversão, do riso, da brincadeira, da esperteza, do descuido da vigilância e da capacidade de buscar e transitar entre performances quando encontraram as brechas nas redes de vigilância.

Quando buscamos saber o que podem as crianças nesse mundo que parece ser feito para "gente grande", nos deparamos com momentos e movimentos e não 
com identidades e comportamentos que possam ser mapeados ou enquadrados em fases. Nos tensionamentos entre as redes do adultocentrismo e uma ética de existir enquanto criança, entendemos que os corpos pequenos, muitas vezes, também veiculam e reiteram as lógicas adultas. Porém, quando conseguem escapar, se divertindo com a seriedade, vemos essas crianças inventivas acontecerem.

O trabalho construído na dissertação nos possibilita trazer para este texto uma discussão da criança enquanto potência de habitar o mundo e subverter as lógicas do poder a partir de movimentos táticos enfatizados pela pesquisa de Certeau (2014). Considerando que a nossa pesquisa se ocupou primordialmente das questões de gênero, sexualidade e da vivência do corpo, contamos com cenas que trazem anúncios desses recortes.

Entretanto, a partir das cenas da pesquisa, podemos trazer desdobramentos que apontem a potência da criança diante do modo de vida ocidental, cujo funcionamento traz fortes marcas do adultrocentrismo como modo reconhecidamente legítimo de experiência e significação do mundo.

A aposta metodológica da dissertação se deu a partir das pesquisas com cotidianos, aos modos de Alves (2015) e Certeau (2014), percebidas como possibilidades para acessar as práticas e narrativas das crianças. Essa forma de produzir conhecimento implica uma disponibilidade do pesquisador para com o campo, de modo que este se torne poroso para as sutilezas, para os detalhes e assim torne-se possível compor uma pesquisa compromissada com as experiências dos praticantes dos cotidianos pesquisados.

Para estar com as crianças, as conversas foram utilizadas como recursos metodológicos. Como aponta Rodrigues (2009), as conversas se diferem de roteiros de entrevista, por exemplo, na medida em que possibilitam que se mude o rumo, o assunto e assim as marcas dos cotidianos vão aparecendo com uma certa liberdade dentro da pesquisa. Dentro das conversas que construíram a pesquisa, escolhemos duas que fazem sentido para pensar a criança em seus movimentos de resistência e reinvenção das realidades. Os encontros que ganham forma de 
conversa nas cenas não foram marcados, aconteceram pela oportunidade e nesse sentido as conversas tornam-se pertinentes, pois permitiram que os praticantes construíssem juntos os caminhos do pesquisar.

Apresentaremos as conversas trazendo algumas companheiras e companheiros para a discussão. Destacamos as contribuições de Certeau (2014), discutindo as táticas, pois entendemos que as crianças conseguem agir taticamente. Também traremos no final do texto apontamentos com Deleuze e Guatarri (2012) sobre o Corpo sem Orgãos e o relacionaremos com a criança, entendendo como ela o produz nesses momentos em que escapa, se encanta, assusta e reinventa mundos. Desse modo, quando a criança se afasta do ideal identitário e organizado, do eu individual e pauta seus movimentos pela experimentação, o Corpo sem Orgãos acontece.

\section{crianças por entre as táticas e as estratégias}

Pensar com as crianças modelos mais inventivos de estar no mundo exige a compreensão do lugar que esses corpos ocupam nos projetos de sociedade. Os regimes do ocidente se organizam tomando o homem adulto, racional e produtivo como referência de existência. Uma rede de dispositivos midiáticos, pedagógicos, legais e médicos se encarrega de assegurar uma relação em que, sendo o adulto o sujeito da razão, a criança torna-se mera aprendiz. A infância é inventada para possibilitar o enquadramento do corpo da criança em uma etapa considerada receptora de conteúdos, numa relação de hierarquia e subordinação aos funcionamentos adultos.

Nossa organização social é de tal modo adultocêntrica, que nossas reflexões sobre a criança e seu universo cultural correm sempre o risco de, repetindo a organização social, situar a criança em condição passiva face à cultura. Pensamos sempre na criança recebendo (ou não recebendo) cultura, e nunca na criança fazendo cultura ou, ainda, na criança recebendo e fazendo cultura ao mesmo tempo. (PERROTTI, 1982, p.18)

Perroti (1982) nos ajuda a pensar o lugar passivo que a criança adquiriu na produção de culturas e realidades. A infância é vista apenas como passagem. O que recebe lugar de importância é o caminho adulto para onde ela se direciona. Nesse regime, não se considera o existir criança em si e suas produções, ela está 
sempre na relação com o adulto. A educação parece ser onde essa concepção se expressa de modo mais nítido. Há um futuro a ser perseguido nas práticas educativas e o questionamento "o que vai ser quando crescer?" traz as marcas fortes da ânsia pelo futuro adulto e provoca um silenciamento do que a criança pode enquanto tal, sem a referência adultocêntrica.

O corpo adulto como referência de existência adquire legitimidade. Tornase o corpo que pode dizer, o que tem a ensinar, o que ocupa uma posição de suposto desenvolvimento completo, há uma relação de poder construída nesse sentido. Entretanto, como aponta Foucault (2006), o poder se configura onde se dá a resistência. Assim, se o corpo adulto ocupa uma posição de poder, também encontraremos resistência de alguma forma. Desse modo, nos arriscamos por buscar, por entre essas tecnologias que incidem controle e disciplina sobre a criança, encontrar as brechas de resistência, as possibilidades de desvios que esses corpos indicam no projeto civilizatório que centrou a existência no adulto individualizado, identitário, produtivo, um corpo organizado como nos aponta Deleuze e Guatarri (2012).

Nesta altura, já podemos situar nossa proposta afirmando que tomamos a criança numa perspectiva diversa da infância. Esta última sustenta a noção da criança angelical; aprendiz; reprodutora direta e passiva de ensinamentos adultos. Vamos nos distanciando da criança das teorias do desenvolvimento, que vai fragmentando o corpo em fases, categorias e expectativas. Queremos a criança acontecendo, resistindo e construindo rachaduras nos funcionamentos que as tomam como simples receptoras de informações; corpos domáveis ou projetos de adultos.

Na compreensão do embate que por vezes se configura entre a vigilância e os escapes das crianças, encontramos uma discussão interessante em Foucault (2010), que aponta os caminhos para que a relação próxima e vigilante entre os pais e a criança se tornasse o modo compreendido como mais saudável e correto de educação, alimentando as exigências de responsabilidade e vigilância parentais para com as crianças e consolidando a infância como uma etapa carente de tais 
redes de vigilância. Sendo assim, Foucault (2010), indica que o crescente interesse pelo tema e a patologização da masturbação infantil a partir do século XVIII tornaram-se os argumentos para restringir os cuidados e a responsabilidade com a criança no estreito núcleo de pais e filhos. A infância, como uma fase especial, carente de vigilância constante e determinante para o futuro adulto é inventada.

Situar a criança na infância é um modo de discipliná-la, tomando como recursos e justificativas, concomitantemente, saberes como a medicina, a psicologia, a pedagogia e o direito. Uma sociedade que tem o adulto como modelo de produção, de consumo e de conhecimento faz da criança o corpo a ser cuidadosamente educado para responder a certos projetos. Por esses projetos, apontamos os regimes de vivência do corpo, das relações de gênero e sexualidade, das relações com trabalho e com a vida em sociedade que precisam da definição de papéis e identidades, geralmente rígidos e reconhecíveis dentro de categorias. Aos modos de Deleuze e Guatarri (2012), o apelo da sociedade ocidental é pelo organismo, pelo corpo individual identitário.

Schérer e Hocquenghem (1976), fazem um trabalho interessante de co-ir questionando os lugares infantis que o corpo da criança ganhou com a consolidação do modelo familiar nuclear. Os autores costuram seu pensamento a partir da criança que borra a prescrição angelical, contrariando o projeto familiar de que são reprodutoras das condutas e valores parentais, as crianças podem desviar para rumos da imprevisibilidade e incerteza.

Os funcionamentos adultocêntricos constituem-se como os fortes nesse jogo. São os estrategistas, aos modos de Certeau (2014), pois a vida adulta produtiva, consumista e racional constitui-se referência do estar no mundo ocidental. Em meio às estratégias do forte, restam as táticas como movimentos dos fracos. Segundo Certeau (2014), as táticas se dão no descuido do forte para desfazer ou deslocar seu jogo. Ele indica a tática como um fazer que: "Tem constantemente que jogar com os acontecimentos para os transformar em 'ocasiões'. Sem cessar, o fraco deve tirar partido de forças que lhe são estranhas" (CERTEAU, 2014, p. 46). Partindo desse conceito, entendemos as crianças como 
sujeitos táticos por excelência. Elas agem no terreno do outro, dispondo do que encontram no caminho, encontram jeitos de jogar o jogo do outro ou de desfazê-lo.

Ao contrário das estratégias, que são produtoras e impositoras, as táticas fazem uso, funcionam no campo do forte, aproveitando seu discurso. (CERTEAU, 2014). Quando assumimos que há uma série de discursos dizendo verdades sobre existir criança, construindo roteiros de relações do que é permitido e do que é proibido, do bom e ruim, compreendemos as investidas do poder pelo campo estratégico. Nos interessamos pela potência de reinventar realidades, produzindo desvios nos roteiros programados quando essas estratégias falham. Compreendemos que se as crianças precisam ser submetidas tão insistentemente a essa rede de tecnologias, discursos e práticas para corresponder ao modelo do organismo adulto, algo em suas existências escapa e pode nos indicar outras experiências e outros modos de estabelecer relação no/com o mundo.

\section{o que podem as crianças?}

$\mathrm{O}$ interesse pelo que podem as crianças não indica que intencionamos apontá-la como o escape total da norma. Segundo Schérer e Hocquenghem (1976), a criança do fora, que viveria no externo das redes de vigilância e controle que conhecemos é uma criança inimaginável. Nos interessar pela potência crianceira implica compreender que ela não está alheia ao poder. Do contrário, como indica Foucault (2006), as relações de poder se dão sem pontos de origem delimitados, de modo complexo, o poder se configura a partir de incidências múltiplas e não é próprio de alguns sujeitos em detrimento de outros.

Assim, percebemos que o controle não estaciona no adulto. É necessário considerar que os corpos reconhecidos como crianças não são simples receptoras, elas também fazem funcionar o controle, a norma e a disciplina. Quando apontamos o adultocentrismo enquanto o jogador forte nessa relação de poder, dizemos de discursos e práticas e não somente dos corpos identificados como adultos. Assim como quando pensamos nos movimentos táticos que as crianças conseguem fazer uso, não buscamos cristalizá-los nos corpos pequenos. A criança pode acontecer no corpo crescido. 
As cenas que apresentaremos a seguir foram compostas por corpos que estão classificados na infância, pois a pesquisa buscou junto desses corpos encontrar a potência da criança, entendendo que eles são os alvos principais das estratégias de vigilância. Nas praças onde aconteceu a pesquisa, foi possível a visualização das alternâncias entre a vigilância e os escapes que, por vezes, as próprias crianças operam. Entretanto, nos interessamos pelas provocações que elas fazem e que extrapolam os limites etários desenvolvimentistas. O que podem as crianças?

A cena a seguir ocorreu tendo como personagens a pesquisadora e crianças pequenas jogando futebol.

- E nesse jogo, podem jogar meninas?

- Não!

- Mas, por que?

- Porque é jogo de brabo, de body builder, jogo de menino é carnívoro.

O jogo continuava e a conversa também.

- Então, menina não pode jogar futebol?

- Pode...até tem o futebol de mulher. A té são carnívoras no futebol de mulheres, mas se for jogar com meninos, elas não aguentam que é de bicho brabo.

O jogo seguiu até que uma menina junto a outra, disse: “Tem que acabar, precisamos ir embora!".

As crianças veicularam e reafirmaram o futebol enquanto esporte culturalmente reconhecido como masculino. Nesse momento, eles operaram com a norma, reproduzindo o discurso machista. Há endurecimento, controle do jogo e subalternização, porém, sendo a bola propriedade de uma das meninas, os jogadores "brabos" não tinham mais com o que jogar. Uma frase foi capaz de desbancar o jogo. Havia muito nessa cena, não aceitam meninas nesse jogo, pactuando a impressão da virilidade como condição, mas o instrumento do jogo não pertencia a eles. Sem bola, o jogo "brabo" perdeu sentido, a interdição direcionada para as meninas e a ostentação da masculinidade não encontrou mais espaço e foi preciso buscar outra coisa para brincar. 
$\mathrm{O}$ jogo dos meninos perdeu o sentido quando o instrumento lhes foi retirado. Eles não detinham todos os elementos necessários para assegurar a continuidade do jogo excludente e, supostamente, mais forte. A bola pertencia ao grupo excluído do jogo e apostamos em dizer que essas meninas expuseram a fragilidade do discurso do modo mais sagaz, expondo que o jogo de "brabos" só aconteceu pois elas cederam o instrumento e acabou quando assim elas quiseram. Foi então que a capacidade inventiva das crianças possibilitou outro brincar. $\mathrm{Na}$ cena que comparece na pesquisa, as crianças foram buscar outra atividade, deixando o bicho "brabo" ir desaparecendo, logo, a preocupação em reafirmar a força e habilidades com o jogo não tinham mais lugar. Apesar de terem funcionado reproduzindo os padrões do que é masculino e do que é feminino, as crianças conseguiram construir outra brincadeira, sem expressarem lamento com os papéis deixados.

Nesses instantes de abertura para a inventividade, a criança acontece. A pesquisa tomou como campo, inicialmente, as praças públicas, mas outros locais ganharam lugar na discussão na medida em que a atenção da pesquisadora não ficava estacionada na geografia da praça. A cena que apresentaremos a seguir não aconteceu na praça, mas muito próximo dela. Uma cena familiar, privada, colocando em evidência a capacidade da criança de rir das seriedades adultas.

- Você é uma menina para usar esse sapato?

- Sim, sou uma menina! (Risos de criancice)

- Então, vou te chamar de menininha!

- Tá bom! (Gargalhadas de criancice)

Um (fe)menino saboreando risos com um sapato. $\mathrm{O}$ tamanho não lhe cabe nas medidas tradicionais, a estética do sapato também parece não caber e o adulto fica alerta. A advertência surge quando o sapato ameaça um projeto de masculinidade que é esperado desse corpo nomeado menino. Riso e um sapato mostraram-se capazes de provocar muitos desdobramentos. $\mathrm{O}$ (fe)menino fez um outro uso do artefato, um uso do brincar. Brincando, ele debocha da estética identitária. Debochando, ele provoca a tolice adulta de pensar que um sapato no pé pode colocar a perder um projeto de masculinidade. Provocando, ele convida 
ao lugar da menininha, como potência e afirmação. Mas não eram só risos e sapatos? Poderiam ser! Mas sempre que a chatice dura adulta comparecer, é possível convidar a criancice para brincar, debochar, provocar, deslocando a urgência em dizer o que é para quem.

As crianças são convocadas, desde muito cedo, a responder aos projetos adultos de civilização, nesse caso, à identificação sexual binária. A preocupação não parece ser com o uso presente do sapato, mas quais caminhos futuros esse uso poderia indicar. Há, nessa cena, a tentativa adultocêntrica de suprimir o movimento da criança, de impedir o desvio da norma.

Nos atentando especificamente às questões de gênero e sexualidade, entendemos que produzir corpos com marcadores específicos, efetuando a divisão entre masculino e feminino não serve somente ao reconhecimento estético. Dizer desses campos bem delimitados é pensar a funcionalidade deles na heterossexualidade enquanto uma matriz para nortear as relações entre sexo, gênero e desejo. A imagem dos opostos macho e fêmea e sua relação perfeita de procriação se asseguram culturalmente quando as identidades são bem definidas. (BUTLER, 2003)

Há o esforço em manter o sistema de identificação binário onde, geralmente, do lado feminino encontramos disponíveis a fragilidade, a disposição para a maternidade, a sensualidade, dentre outras expectativas. Nos campos do masculino, a agressividade, a figura de protetor e provedor. Inventa-se a cena de uma completude, não só biológica, mas subjetiva e cultural, entre um e outro.

A noção de que pode haver uma "verdade" do sexo, como Foucault a denomina ironicamente, é produzida precisamente pelas práticas reguladoras que geram identidades coerentes por uma via de uma matriz de normas de gênero coerentes. A heterossexualização do desejo requer e institui a produção de oposições discriminadas e assimétricas entre "feminino" e "masculino", em que estes são compreendidos como atributos expressivos de "macho" e de "fêmea". (BUTLER, 2003, p. 38/39)

Apenas um sapato foi suficiente para abalar as sustentações da verdade do sexo no corpo do (fe)menino. O pai o confrontou, pois ele ousou o terreno estrangeiro, foi transgressor. Mesmo possuindo pés como uma condição 
anatômica para usar o objeto, o sapato não lhe cabe no sentido estético e político da masculinidade adulta. Faz parte do conjunto de objetos, de práticas e de posturas de meninas/mulheres. O pai adverte e ameaça. A criança ri! Os ruídos perturbadores desse riso fazem conexões com um outro que perturba e viola os contornos já conhecidos, a bicha, em Zamboni (2016). A bicha recusa identificações que tentam lhe indicar e, ao tentar situá-la, ela já escapou, pois ela só funciona nos limites, nas fronteiras e não nos territórios demarcados. Uma criança, enquanto potência de inventar, de subverter, de rir dessa seriedade adulta estranha contida no calçar de um sapato, poderia ser uma criança-bicha?

Assim como a criança, tentam apreender a bicha, mas seus contornos sempre saem do planejado. A criança que ainda não se tem certeza do que será, no projeto adultocêntrico de produzir identidades, torna-se muitas, torna-se possibilidade. A bicha, por sua vez, transitando nos terrenos femininos e masculinos, constrói uma outra coisa, um outro modo de viver o corpo que desafia o binarismo e se faz corpo de possíveis. "Apesar de remetê-la a uma cultura de representação e da reprodução, a bicha persiste nos saberes da sexualidade até os nossos dias como singularidade incontornável por completo." (ZAMBONI, 2016, p. 19). Nos parece que as crianças e as bichas podem sim se constituir como uma potência de deslocamento dos processos de endurecimento da vida, de sedimentação de funções e ações dos/nos corpos a partir do sexo biológico. As bichas e as crianças, tomadas em seus movimentos e deslocamentos, parecem poder nos dizer de outro projeto político de civilização.

Na referida pesquisa são destacadas as questões de gênero e sexualidade, pois compreendemos que essas são as primeiras verdades a serem buscadas e reafirmadas sobre os corpos, como afirma Butler (2003). Até mesmo antes de nascer, uma criança já pode ser submetida ao enquadramento no sistema de sexo e gênero binário. Devidamente identificada, as investidas se dão para que tal verdade não fuja do rumo proposto, que é de se formarem corpos de homens e mulheres adultos seguros e completos em suas identidades. Por vezes, vimos as crianças atuarem como veículos das verdades adultas, se valendo das estratégias 
do controle. Entretanto, também foi possível perceber de modo relevante, a capacidade da criança de subverter todo o jogo, se divertindo com ele. Não se trata então, de buscar a destruição das estruturas adultocêntricas, mas de pensarmos formas de coexistir que possibilitam uma ética crianceira nos modos de estar no mundo. Para nos auxiliar nessa empreitada, traremos a seguir uma discussão com o conceito de Corpo sem Orgãos de Deleuze e Guatarri (2012), que não pretende esgotá-lo, mas tomá-lo como um caminho possível para a articulação com as potências das crianças.

\section{a criança e a produção do corpo sem orgãos}

Crianças aprontam, zombam, escapam do roteiro, provocam espanto e constrangimento. Existindo sempre em relação, relembram ao adulto o que os coloca em tal posição. São educadas, advertidas, vigiadas, punidas e corrigidas por uma vasta e densa rede de cuidadores e, ainda assim, elas conseguem aproveitar brechas, fazer furos nas redes de controle da infância. Brincando com as lógicas adultocêntricas, serializadas e endurecidas de fabricar corpos, as crianças convidam-nos a uma conversa com Gilles Deleuze e Felix Guatarri (2012) por um corpo que possa experimentar mais do que reproduzir ou interpretar. Os autores propõem o conceito de Corpo sem Órgãos enquanto exercício de viver a experiência do corpo de outros modos. Deleuze e Guatarri (2012) atacam a ideia de organismo, de corpo organizado, que justificam os regimes de identificação e as normas de conduta.

A afirmativa do organismo é o que solicita, dentre outras coisas, que o corpo seja nomeado ainda na ultrassonografia em relação ao sexo/gênero. Esta é a primeira organização que se busca imprimir sobre o corpo e assim constrói-se a ideia de identidade sexual. A consolidação dessa identidade torna desviante qualquer expressão que não se enquadre. Uma leitura é feita sobre o corpo, sobre suas partes, sobre os genitais, torna-se um corpo estratificado, funcional, um corpo onde cada órgão adquire uma finalidade e, desse modo, qualquer uso dissidente, torna-se o desvio. O alerta é de: "Você será organizado, você um organismo, articulará seu corpo - senão você será um depravado. Você será significante e 
significado, intérprete e interpretado - senão será um desviante." (DELEUZE; GUATARRI, 2012, p. 25).

O apelo pela identidade sexual salta como primordial na preocupação com o corpo, mas não é o único. As funções parentais; os modos de educar; as formas de governo; as relações das profissões em seus especialismos; dentre muitas outras convocações, são exemplos dos papéis atribuídos aos corpos. O agravante é que são papéis que, uma vez atribuídos, adquirem o reconhecimento de legitimidade e tornam-se verdades a serem asseguradas e reafirmadas sobre os corpos.

Dessa forma, entendemos que o tornar-se adulto implica perder a capacidade de brincar de faz-de-conta, de inventar realidades e trocar de papéis como as crianças. Somos convocados a existir a partir de regimes de espelhamento e de reprodução, para isso as práticas educativas funcionam de modo a responder a supostos modelos. Nos dizem a função de cada pedaço do corpo. Desse modo, vai sendo investido em cada estratégia de formação o ideal do organismo, de identidade para moldar o corpo que pode ser reconhecido e circular como adequado, um corpo conformado. Os regimes adultocêntricos alimentam-se do corpo identificável.

A criança, em sua ousadia, não aceita gratuitamente. Ela guarda consigo a potência de experimentar, para além do roteiro. Desse modo é que aproximamos a criança do conceito de Corpo Sem Órgãos. Contudo, o processo de experimentar não ocorre isento da vigilância dos olhares endurecidos. Deleuze; Guatarri (2012, p. 12) dizem ser o Corpo sem Órgãos: “Uma experimentação não somente radiofônica, mas biológica, política, atraindo sobre si censura e repressão. Corpus e Socius, política e experimentação. Não deixarão você experimentar em seu canto.". O Corpo sem Órgãos não aparece como um conceito, mas como uma prática. Deleuze; Guatarri (2012) tomam uma discussão já feita por Antonin Artaud, em 1947, atacando os órgãos, mais especificamente o organismo que os organizam e lhes dão funcionalidade. No desdobramento feito sobre essa proposta, o Corpo sem Órgãos torna-se o modo de se desfazer do ideal do eu que é reiterado como condição de existência. A ideia do eu constitui-se na ideia de 
essência do sujeito, a verdade que precisa ser descoberta e então reafirmada constantemente. A dúvida sobre um corpo torna-se aterrorizante e saberes como a psicanálise, a medicina, a pedagogia são os indicados para trazer o sujeito de volta para o caminho de seu eu. Onde encontramos estratégias de buscar a universalização dos corpos a partir do ideal do eu, o Corpo sem Órgãos diz "não!" e apresenta um caminho de desfazer qualquer aproximação desse eu.

Experimentar o corpo sem órgãos é dar passagem ao desejo em seu processo de produção, sem referência a uma exterioridade ou a algo anterior. É, também, um deslocamento da noção de que o desejo é falta, de que ele carece de ser preenchido. Trata-se da reivindicação do corpo em sua potência de sentir, em suas intensidades. Enquanto o organismo se ocupa das formas, das funções, de retirar do corpo uma utilidade, o corpo sem órgãos denuncia o roubo do corpo enquanto potência de experimentar e desejar. (DELEUZE, GUATARRI, 2012). Ao invés do eu essencial, do desejo carente de uma referência externa, encontramos a possibilidade de uma experiência de corpo em si, de intensidades e produções desejantes que mobilizam, deslocam, inventam e rompem lugares cristalizados.

\section{desejando-nos crianças, inconclusos, seguimos.}

Neste sentido é que apostamos que as crianças conseguem construir para si, aos modos de Deleuze e Guatarri (2012), um Corpo sem Órgãos. Dizer isso não implica afirmar que elas estão totalmente libertas do organismo. Mas, sobretudo, que elas conseguem, em meio às organizações e significados que lhes são atribuídos, produzir rotas de fugas, experimentações que fazem torções nos próprios significados e assim mobilizam, na localidade e na momentaneidade, que os significados, organizações e sujeições não sejam mais suficientes. Em seus movimentos de vida, a criança fabrica para si um Corpo sem Órgãos e produz reinvenções no que as lógicas adultocêntricas tomam como carência para a existência.

Deleuze e Guatarri (2012), apontam que a construção do Corpo sem Órgãos precisa acontecer com prudência. Desestabilizar o que sustenta o organismo não deve implicar na morte do corpo. É preciso conservar, segundo eles, algo do 
organismo para que se sobreviva em uma realidade dominante. Dessa forma, pensamos uma aproximação possível entre os autores e Butler (2003), quando ela nos indica que as identidades vão existir e que a subversão delas ocorre por dentro, deslocando e questionando suas verdades enquanto elas tentam se assegurar nos corpos. Também é possível se recordar de Certeau (2014), que se referindo às práticas nos permite pensar na criança agindo dentro do jogo do outro. Ela não o anula totalmente, mas o desestabiliza, o questiona e o desloca.

Nesse mesmo sentido, Deleuze e Guatarri (2012) dizem ser o Corpo sem Órgãos o ovo, mas é o ovo tomado em si mesmo, não em uma noção evolucionista de que ele se tornará organismo definido. O ovo, que possui em si apenas limiares e migrações, não se apresenta como uma representação ou reprodução do que lhe antecede. Tomado em si é a potência de ser, rompendo com qualquer previsão de forma conhecida. Neste sentido, os autores apontam o Corpo sem Órgãos como bloco de infância, carregando a potência do tornar-se. A criança, como o ovo, se configura como essa via de imprevisibilidade, de caminhos diversos, de risco iminente e poucas certezas. Importante pontuar que pensar o ovo e a criança como Corpo sem Órgãos não implica uma simples regressão aos estágios conhecidos como iniciais da existência. Não se volta ao ovo ou à criança quando já está dado o organismo para que então se construa o corpo sem órgãos. Eles existem juntos, podem se produzir em um regime de coabitação (DELEUZE; GUATARRI, 2012). Dessa forma é que os corpos podem, mesmo como adultos, em um mundo feito para adultos, experimentar movimentos crianceiros, negociando a urgência de certezas e de modelos de vida, fazendo riso com os endurecimentos a que são convocados.

O Corpo sem Órgãos é bloco de infância, devir, o contrário da recordação de infância. Ele não é criança "antes" do adulto, nem "mãe" "antes" da criança: ele é a estrita contemporaneidade do adulto, da criança e do adulto, seu mapa de densidades e intensidades comparadas, e todas as variações sobre este mapa (DELEUZE; GUATARRI, 2012, p. 31).

Com isso, podemos dizer que a criança, enquanto escape, enquanto brecha e surpresa fornece-nos uma lógica possível para a construção de Corpo sem Órgãos. A criança em sua potência de experimentação é um caminho possível 
quando pensamos uma revolução do corpo que proponha alternativas às políticas identitárias. Nos atrevemos a dizer que os movimentos sociais como, por exemplo, o movimento feminista, tem muito a aprender com as crianças. Não se trata de pensar outras identidades na lógica de inversão, mas, aos modos da criança, de estar dentro da relação de poder e, dessa forma, conseguir fazer brechas e expor as fragilidades do próprio poder. A partir de Foucault (2006, p.183), compreendemos que,

O poder deve ser analisado como algo que circula, ou melhor, como algo que só funciona em cadeia. Nunca está localizado aqui ou ali, nunca está nas mãos de alguns, nunca é apropriado como riqueza ou bem. O poder funciona e se exerce em rede. Nas suas malhas os indivíduos não só circulam, mas estão sempre em posição de exercer este poder e de sofrer sua ação; nunca são alvo inerte ou consentido do poder, são sempre centros de transmissão. Em outros termos, o poder não se aplica aos indivíduos, passa por eles.

Selvino Assmann, em um prefácio escrito para uma edição brasileira de um livro de Giorgio Agamben, consegue traduzir bem, a partir da obra, as possibilidades que as crianças podem suscitar em uma realidade onde o adulto adquiriu muita certeza de si e com isso tornou-se endurecido, incapaz de práticas de transformação.

Profanar é assumir a vida como jogo, jogo que nos tira da esfera do sagrado, sendo uma espécie de inversão do mesmo. Convidandonos a profanar, Agamben alerta para o fato de termos perdido a arte de viver, que é a da infância, lugar primeiro da mais séria profanação da vida, como já fora anunciado pelo Zaratrusta de Nietzsche, e retomado por Benjamin, de quem Agamben não é só estudioso, mas se sente inspirado em seu "messianismo imanente": as crianças sabem jogar e brincar, enquanto os adultos, sérios, perderam a capacidade de ser mágicos e fazerem milagres. (Assmann, 2007, p. 13)

Sem conclusões, apenas com questionamentos, ficamos com uma provocação construída a partir de diálogo entre Gilles Deleuze e Michel Foucault nos dizendo como as crianças podem deslocar o sistema de ensino planejado para elas, mas, muitas vezes, sem que elas próprias sejam ouvidas. Apostamos que, além do sistema de ensino, as crianças podem de modo relevante e intenso, fazer tremer diversas outras práticas, discursos e relações que pautam nossa existência. 
"Se as crianças conseguissem que seus protestos, ou simplesmente, suas questões fossem ouvidas em uma escola maternal, isso seria o bastante para explodir o conjunto do sistema de ensino" (DELEUZE, 1979, p. 72).

\section{referências}

ASSMANN, Selvino. Prefácio. In: AGAMBEN, Giorgio. Profanações. São Paulo: Boitempo, 2007.

ALVES, Nilda. Questões teórico-metodológicas nas/das/com as pesquisas em educação. In: GARCIA, Alexandra; OLIVEIRA, Inês Barbosa de. (org.). Nilda Alves: praticantepensante de cotidianos. Belo Horizonte: Autêntica, 2015. p.133 a 169.

BUTLER, Judith. Problemas de Gênero: Feminismo e Subversão de Identidade. Rio de Janeiro: Civilização Brasileira, 2003.

BUTLER, Judith. Corpos em aliança e a politica das ruas: notas para uma teoria performativa de assembleia. Rio de Janeiro: Civilização Brasileira, 2018.

CERTEAU, Michel de. A invenção do cotidiano: 1 Artes de Fazer. 22 ed. Petrópolis: Vozes, 2014.

DELEUZE, Gilles; FOUCAULT, Michel. Os intelectuais e o poder. In: FOUCAULT, M. Microfísica do Poder. Rio de Janeiro: Edições Graal, 1979.

DELEUZE, Gilles; GUATARRI, Félix. Mil Platôs: capitalismo e esquizofrenia 2, vol. 3. São Paulo: Editora 34, 2012.

FOUCAULT, Michel. Microfísica do poder. 22ª ed. Rio de Janeiro: Paz e Terra, 2006.

FOUCAULT, Michel. Ditos e escritos, volume IX: genealogia da ética, subjetividade e sexualidade/Michel Foucault: Rio de Janeiro: Forense Universitária, 2014.

FOUCAULT, Michel. Os anormais. São Paulo: Martins Fontes, 2010.

SCHÉRER, René.; HOCQUENGHEM, Guy. Co - ire Albúm sistemático de la infância. Barcelona: Editora Anagrama. 1976.

PERROTTI, Edmir. A criança e a produção cultural. In: ZILBERMAN, Regina (org.) A produção cultural para a criança. Porto Alegre: Mercado Aberto, 1982. p. 9-27.

RODRIGUES, Alexsandro. Sexualidade(s) e Currículo(s): práticas cotidianas que nos atravessam produzindo experiências. Orientador: Carlos Eduardo Ferraço. Tese (doutorado) - Universidade Federal do Espírito Santo, Centro de Educação: Vitória, 2009.

ZAMBONI, Jésio. Educação Bicha: uma a(na[1])rqueologia da diversidade sexual. Tese (Doutorado em Educação) - Universidade Federal do Espírito Santo, Centro de Educação, 2016.

recebido em: 11.08.2019

aprovado em:.07.11.2019 